\title{
Innate immune response is differentially dysregulated between bipolar disease and schizophrenia
}

\author{
Angelica de Baumont ${ }^{\mathrm{a}, 1}$, Mariana Maschietto ${ }^{\mathrm{a}, \mathrm{b}, 1}$, Leandro Lima ${ }^{\mathrm{b}}$, Dirce Maria Carraro ${ }^{\mathrm{b}}$, Eloisa Helena Olivieri ${ }^{\mathrm{b}}$, \\ Alex Fiorini ${ }^{\mathrm{b}}$, Luiz André Nardin Barreta ${ }^{\mathrm{b}}$, Joana Almeida Palha ${ }^{\mathrm{c}, \mathrm{d}}$, Paulo Belmonte-de-Abreu ${ }^{\mathrm{e}}$, \\ Carlos Alberto Moreira Filho ${ }^{\mathrm{f}}$, Helena Brentani ${ }^{\mathrm{a}, \mathrm{g}, *, 1}$ \\ a Institute of Psychiatry - University of Sao Paulo, Medical School (FMUSP), São Paulo (SP), Brazil \\ ${ }^{\mathrm{b}}$ Laboratory of Genomics and Molecular Biology/CIPE - AC Camargo Hospital Cancer Center, Sao Paulo (SP), Brazil \\ ${ }^{c}$ Life and Health Sciences Research Institute (ICVS), School of Health Sciences, University of Minho, Braga, Portugal \\ 'ICVS/3B's - PT Government Associate Laboratory, Braga/Guimarães, Portugal \\ e Department of Psychiatry, Federal University of Rio Grande do Sul, PortoAlegre, Brazil \\ ${ }^{\mathrm{f}}$ Department of Pediatrics, University of Sao Paulo, Medical School (FMUSP), Sao Paulo (SP), Brazil \\ ${ }^{g}$ LIM23 - University of Sao Paulo, Medical School (FMUSP), and Instituto Nacional de Psiquiatria para Infancia e Adolescencia, Sao Paulo (SP), Brazil
}

\section{A R T I C L E I N F O}

\section{Article history:}

Received 24 May 2014

Received in revised form 22 September 2014

Accepted 28 October 2014

Available online xxxx

\section{Keywords:}

schizophrenia

bipolar disorder

co-expression

protein-protein interaction (PPI)

network

\begin{abstract}
A B S T R A C T
Schizophrenia (SZ) and bipolar disorder (BD) are severe psychiatric conditions with a neurodevelopmental component. Genetic findings indicate the existence of an overlap in genetic susceptibility across the disorders. Also, image studies provide evidence for a shared neurobiological basis, contributing to a dimensional diagnostic approach. This study aimed to identify the molecular mechanisms that differentiate SZ and BD patients from health controls but also that distinguish both from health individuals. Comparison of gene expression profiling in post-mortem brains of both disorders and health controls (30 cases), followed by a further comparison between 29 BD and 29 SZ revealed 28 differentially expressed genes. These genes were used in co-expression analysesthat revealed the pairs CCR1/SERPINA1, CCR5/HCST, C1QA/CD68, CCR5/S100A11 and SERPINA1/TLR1 as presenting the most significant difference in co-expression between SZ and BD. Next, a protein-protein interaction (PPI) network using the 28 differentially expressed genes as seeds revealed CASP4, TYROBP, CCR1, SERPINA1, CCR5 and C1QA as having a central role in the diseases manifestation. Both co-expression and network topological analyses pointed to genes related to microglia functions. Based on this data, we suggest that differences between SZ and BP are due to genes involved with response to stimulus, defense response, immune system process and response to stress biological processes, all having a role in the communication of environmental factors to the cells and associated to microglia.
\end{abstract}

(c) 2014 Elsevier B.V. All rights reserved.

\section{Introduction}

Schizophrenia (SZ) and bipolar disorder (BD) are severe psychiatric conditions, with a lifetime prevalence of about 1\% (Merikangas et al., 2007; Alaerts and Del-Favero, 2009; Doherty et al., 2012). Both disorders have a neurodevelopment component, with onset of symptoms occurring most frequently during late adolescence or early adulthood (Maier et al., 2006; Doherty et al., 2012). Family studies demonstrate that the recurrence risk in families of SZ patients is $8-12 \%$ and the recurrence risk in BD families is approximately 10\% (Barnett and Smoller,

\footnotetext{
* Corresponding author at: Institute of Psychiatry, University of Sao Paulo, Medical School (FMUSP), Rua DrOvidio Pires de Campos, 785 - CEP 05403-010 São Paulo, SP, Caixa Postal n 3671, Brasil. Tel.: + 55113069 6962; fax: + 551130698040 .

E-mail address: helena.brentani@gmail.com (H. Brentani).

1 These authors contributed equaly to this paper.
}

2009; Ivleva et al., 2010). The estimates of heritability range between 40 - 80\% for both diseases (Sullivan et al., 2003; Bienvenu et al., 2011) with genetic findings indicating an overlap in familial-genetic susceptibility across the diseases (O'Donovan et al., 2008; Lichtenstein et al., 2009; Ivleva et al., 2010). In addition, chromosomal regions, including risk variants show linkage to both BD and SZ (Barnett and Smoller, 2009; Moskvina et al., 2009; Williams et al., 2011a,b). Global gene expression analyses revealed common genes for SZ and BD, which were associated with synapse, neuronal and glial functions, metabolism, cellular and mitochondrial function, nervous system development, immune system development and response, and cell death (Iwamoto et al., 2005; Choi et al., 2008; Shao and Vawter, 2008; Lin et al., 2012).

Due to the similarities between both disorders, gene expression profiling of BD and SZ were first compared as one entity to controls to identify common alterations. Further, genes from this comparison were analyzed in co-expression and protein-protein interaction (PPI) networks contexts allowing the identification of changes in expression 
and biological processes potentially involved in the different clinical phenotypes observed in SZ and BD.

\section{Material and methods}

\subsection{Sample}

RNA samples were obtained from the frontal cortex of 104 subjects from the Stanley Neuropathology Consortium. Potential donors for the brain collection were identified by the pathologist who contacts the family of the deceased, request permission for donation, make a preliminary diagnosis and require psychiatric records; if necessary a psychiatrist contacts one or more family members and make a telephone call to clarify the symptoms. All records are reviewedfor DSM-IV psychiatric diagnosis independently by two senior psychiatrists. For normal controls, a structured telephone interview with a first-degree family member was carried out in all cases. Detailed sample collection is available in (Torrey, 2000). RNA concentration was determined by spectrophotometry (Nanodrop, Thermo Scientific, US), and integrity was accessed using the 2100 Bioanalyzer (Agilent Technologies, Waldbronn, Germany). Due to low RNA integrity, 16 samples were discarded. The final samples included 30 non-psychiatric controls, 29 bipolar patients and 29 schizophrenic patients. A summary of subject characteristics is shown in Table 1.

The study protocol was approved by the ethics committee of A.C.Camargo Cancer Center and was performed in accordance with the Declaration of Helsinki.

\section{2. cDNA microarray experiments}

The Agilent 4x44K human oligonucleotide microarray assay was used (Agilent 4112 F; Agilent Technologies, CA) for microarray analyses. Slides were scanned with the Agilent Bundle Microarray Scanner System (Agilent Technologies) and data were processed using the Feature Extraction 10.7.3.1 software (Agilent Technologies). Among the 45,015 spots present in each array, only those with none flag for quality control (i.e. low intensity, saturation, controls, etc.) were selected for analysis. For analysis of replicate spots, the average intensity after background correction was calculated, normalization was performed using locally weighted linear regression (LOWESS) with $\alpha=0.2$ within slides using the $\mathrm{R}$ software version 2.11.1 ( $\mathrm{R}$ Development Core Team, 2010). For statistical analyses only transcripts that were presented in at least 24 cases of each group were considered. In total, 22,639 transcripts were analyzed. Gene expression data described in this study are available from GEO with accession ID GSE6210.

\subsection{Statistical analysis}

For analysis of genes related to pathological changes, patients with either BD or SZ (PSY) were compared to individuals without pathology (CON). From this list of differentially expressed genes, BD and SZ patients were compared to identify possible disease-specific genes.

Table 1

Summary of subject characteristics.

\begin{tabular}{llll}
\hline & $\begin{array}{l}\text { Bipolar } \\
\text { patients }\end{array}$ & $\begin{array}{l}\text { Schizophrenic } \\
\text { patients }\end{array}$ & $\begin{array}{l}\text { Non-psychiatric } \\
\text { controls }\end{array}$ \\
\hline Number of Samples & 29 & 29 & 30 \\
Age & 44,46 & 42,17 & 44,43 \\
Gender & $52 \%$ Male & $79 \%$ Male & $76 \%$ Male \\
Race & $93 \%$ White & $96 \%$ White & $100 \%$ White \\
PMI & $36,89 \pm 18,26$ & $31,40 \pm 16,93$ & $29,97 \pm 12,71$ \\
Brain pH & $6,49 \pm 0,25$ & $6,45 \pm 0,25$ & $6,61 \pm 0,28$ \\
\hline
\end{tabular}

For each variable, mean \pm standard error or percentage value is reported. PMI: postmortem interval.
Analyses using Multiple Significant Analysis of Microarray (SAM) identified differentially expressed genes. Five hundred permutations were performed using a False Discovery Ratio (FDR) of $1 \%$ for both the PSY vs. CON and BD vs. SZ analyses. To assess similarity patterns, Pearson correlation and complete linkage were used for nonsupervised hierarchical clustering, and reliability was assessed by bootstrapping using multiExperiment Viewer (MeV) software (Saeed et al., 2003).

Differentially expressed genes were annotated using biological process categories in the Gene Ontology Database (GO) and a hypergeometric test with multiple test adjustments was applied to find overrepresented chromosome regions with WebGestalt, using the human genome as reference, p-value $<0.05$ and Benjamin Hochnerg adjustment (Zhang et al., 2005).

To assess differences in network organization between individuals with BD and SZ, co-expression of pairs of genes were evaluated as previously described (Silva et al., 2012). Briefly, the Pearson Correlation Coefficient (PCC) for each gene and partners in each group was calculated. PCC absolute difference between groups was used to identify genes whose co-expression was different between BD and SZ. To identify genes that were significantly different between patient groups, an empirical p-value distribution was created as follows: cases were randomly assigned to two groups and the PCC was calculated for each group and a difference ranking was calculated. These analyses were repeated 1,000 times to create a random distribution of PCC's difference rankings. Real PCC differences for genes between patient groups were compared to the random distribution to generate p-values (Supplemental table 1) defining a network of genes whose co-expression was significantly different ( $\mathrm{p} \leq 0.05$ ) between SZ and BD. The network was visualized using Cytoscape (Cline et al., 2007).

To identify additional properties potentially associated with the differentially expressed genes between SZ and BD, a Protein-Protein Interaction (PPI) networkwas used. By querying three human interactome databases: HPRD (Keshava Prasad et al., 2009), MINT (Licata et al., 2012) and IntAct (Kerrien et al., 2012), a network starting with differentially expressed genes (seeds) and their first neighbors (genes with direct interaction in the interactome databases) and genes that connected first neighbors from seed was constructed. To identify broker (i.e., a gene that connects different genes that do not connect directly with each other) and bridge (i.e., a gene that has only a few connections but connects broker genes and their associated partners (i.e., hubs)) genes, previously published algorithms (Cai et al., 2010) were used in the Interactome Graph website (http://bioinfo.lbhc.hcancer.org.br/ interactomegraph/). Top 5\% genes were selected. Using the entire set of genes available in the three banks $(14,276)$, the probability of a node appearing in a random network was estimated by generating 1,000 networks using a random collection of 25 genes (an equivalent number of genes differentially expressed found in this study and present at the PPI data). For each gene in the original network, the number of times it appeared in the 1,000 networks was computed. Genes that appeared more than $20 \%$ times ( 5 th percentile) were considered random, because the gene has a high probability of appearing in any human PPI.

\section{Results}

\subsection{Characterization of differentially expressed genes between $B D$ and $S Z$}

Gene expression profile analyses of PSY (i.e., BD and SZ) versus CON identified 1,264 differentially expressed genes. These genes were involved with nervous system, vasculature and ectoderm development, regulation of metabolism and the immune system biological processes.

Of the 1,264 genes, 28 were differentially expressed when comparing individuals with $\mathrm{BD}$ and $\mathrm{SZ}(\mathrm{FDR}<1 \%)$, all having a higher expression in $\mathrm{BD}$. These genes are involved with immune system response, immune system regulation, and response to stimulus (Table 2). Non- 
Table 2

Genes differentially expressed between BD and SZ with respective genomic location, fold change and main biological processes according Gene Ontology functional annotation.

\begin{tabular}{|c|c|c|c|c|}
\hline Gene Symbol & Gene ID & Location & $\mathrm{BD} / \mathrm{SZ}$ & GO Biological Processes \\
\hline SST & 6750 & $3 q 28$ & 1,36 & response to stimulus, locomotion, response to stress \\
\hline APOC1 & 341 & $19 q 13.2$ & 1,42 & Apolipoprotein C1 associated to LOAD (late onset Alzheimer Disease) \\
\hline A_24_P41890 1 & Not_found & & 1,46 & None informed \\
\hline PGDS & 27306 & $4 q 22.3$ & 1,48 & Apoptosis-increase ROS, IL6, TNFa \\
\hline AK126405 & 1240 & $12 \mathrm{q} 24.1$ & 1,50 & Chemokine-like receptor 1 - CMKLR1 - multifunctional receptor with pro-anti-inflammatory effect \\
\hline S100A11 & 6282 & $1 \mathrm{q} 21$ & 1,51 & response to stimulus \\
\hline$C C D C 71$ & 64925 & 3p21.31 & 1,54 & Coiled coil domain containing 71 \\
\hline LAIR1 & 3903 & $19 q 13.4$ & 1,55 & Leucocyte Associated IG like receptor1 immune inhibitory receptor \\
\hline CMTM7 & 112616 & $3 \mathrm{p} 22.3$ & 1,59 & response to stimulus, locomotion \\
\hline$U 80773^{1}$ & Not_found & chr1:83151695-83151636 & 1,61 & None informed \\
\hline AIF1 & 199 & $6 \mathrm{p} 21.3$ & 1,63 & $\begin{array}{l}\text { immune response, immune system process, regulation of immune system process, response to stimulus, } \\
\text { response to stress }\end{array}$ \\
\hline$H L A-D M B$ & 3109 & $6 \mathrm{p} 21.3$ & 1,63 & immune response, immune system process, response to stimulus \\
\hline PYCARD & 29108 & $16 \mathrm{p} 11.2$ & 1,63 & $\begin{array}{l}\text { immune response, immune system process, regulation of immune system process, response to stimulus, } \\
\text { response to stress }\end{array}$ \\
\hline CYBB & 1536 & Xp21.1 & 1,65 & immune response, defense response, immune system process, response to stimulus, response to stress \\
\hline CASP4 & 837 & $11 q 22.2-q 22.3$ & 1,66 & $\begin{array}{l}\text { Inflammation and natural immunity regulation activates CASPASE1, that in turn activates IL1b } \\
\text { and IL18 that regulat inflammation and immunity }\end{array}$ \\
\hline TREM2 & 54209 & $6 \mathrm{p} 21.1$ & 1,68 & immune response, immune system process, response to stimulus, locomotion \\
\hline CCR5 & 1234 & $3 \mathrm{p} 21.31$ & 1,69 & immune response, immune system process, defense response, response to stimulus, response to stress \\
\hline HCST & 10870 & $19 q 13.1$ & 1,71 & immune response, immune system process, regulation of immune system process, response to stimulus \\
\hline TLR1 & 7096 & $4 \mathrm{p} 14$ & 1,73 & $\begin{array}{l}\text { immune response, immune system process, regulation of immune system process, response to stimulus, } \\
\text { response to stress }\end{array}$ \\
\hline SERPINA1 & 5265 & $14 \mathrm{q} 32.1$ & 1,75 & response to stimulus, response to stress \\
\hline CD14 & 929 & $5 q 31.1$ & 1,75 & $\begin{array}{l}\text { immune response, immune system process, regulation of immune system process, response to stimulus, } \\
\text { response to stress }\end{array}$ \\
\hline CCR1 & 1230 & $3 p 21$ & 1,77 & $\begin{array}{l}\text { immune response, immune system process, regulation of immune system process, response to stimulus, } \\
\text { response to stress }\end{array}$ \\
\hline TYROBP & 7305 & 19q13.1 & 1,77 & $\begin{array}{l}\text { immune response, immune system process, regulation of immune system process, response to stimulus, } \\
\text { response to stress }\end{array}$ \\
\hline RGS1 & 5996 & $1 \mathrm{q} 31$ & 2,05 & immune response, immune system process, response to stimulus \\
\hline$C 1 Q A$ & 712 & $1 \mathrm{p} 36.12$ & 2,08 & $\begin{array}{l}\text { immune response, immune system process, regulation of immune system process, response to stimulus, } \\
\text { response to stress }\end{array}$ \\
\hline CD68 & 968 & $17 \mathrm{p} 13$ & 2,09 & response to stimulus \\
\hline PSPH & 5723 & $7 \mathrm{p} 11.2$ & 2,30 & response to stimulus \\
\hline CAMK2N2 & 94032 & $3 q 27.1$ & 3,57 & $\begin{array}{l}\text { Calcium calmodulin dependent protein kinase II inhibitor } 2 \text { regulation of synaptic plasticity implicated in } \\
\text { neurodegeneration }\end{array}$ \\
\hline
\end{tabular}

1 Probes in the platform without identified gene.

supervised hierarchical clustering based on the expression of these 28 genes did not reveal different patterns of gene expression between SZ and BD (Supplemental Fig. 1).
To identify chromosome regions potentially involved in the differentiation between BD and SZ, the 28 genes were mapped revealing overrepresentation of genes located at 3p21 ( $<<0.001)$; CCDC71, CCR1

A.

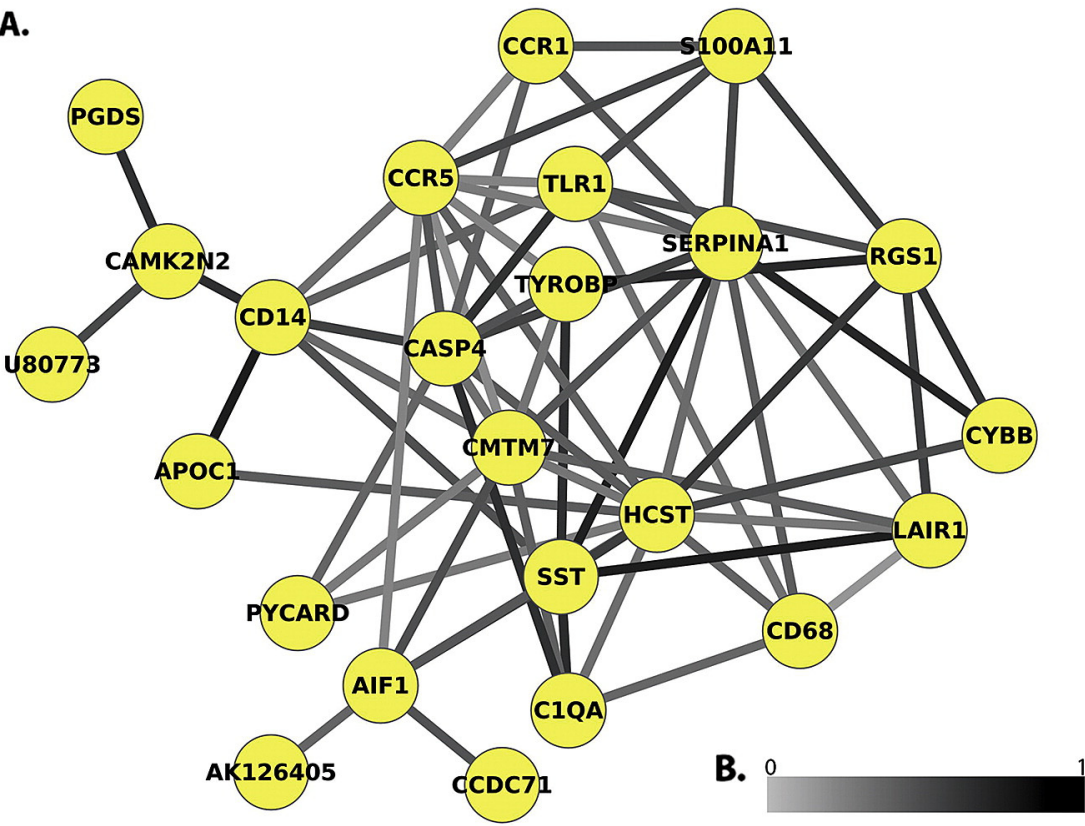

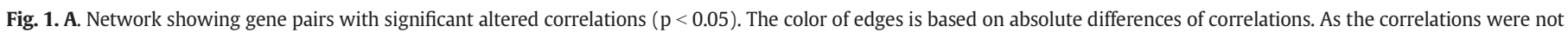
inverted but increased, the color of edges represents the difference in absolute correlation. B. Legend of colors of edges. 
and CCR5 found in our analyses in this region were part of the chemokine receptor gene cluster.

3.2. Construction of networks based on the differentially expressed genes between $B D$ and $S Z$ patients

\subsubsection{Co-expression gene network}

To identify differences in co-expression among the 28 genes (see Material and Methods), we used Pearson Coefficient Correlation (PCC) between gene pairs in $\mathrm{SZ}$ and $\mathrm{BD}$. This analysis revealed 65 significant gene pairs $(\mathrm{p}<0.05)$ between $\mathrm{SZ}$ and $\mathrm{BD}$, with the gene pairs CCR1/ SERPINA1, CCR5/HCST, C1QA/CD68, CCR5/S100A11 and SERPINA1/TLR1 presenting the most significant differences of co-expression between the disorders (Supplemental Table 1). These were used to construct a co-expression network (Fig. 1). It is importantto note that the significant differences in co-expressed gene pairs between SZ and BP presented the same sign, suggesting that it represents variances in the magnitude of the co-expression rather than inversion of the PCC. Of note, there were not gene pairs that correlated in a positive way in one disorder and in a negative way in the other.

\subsubsection{PPI network}

To better address the cellular mechanisms involved in the differences between SZ and BD, 25 out of 28 differentially expressed genes were found to be represented in the human PPI databases and used as seeds to construct an interaction network rendering 285 genes (Fig. 2). This set of 285 genes has over-representation of response to stimulus, defense response, immune system process and response to stress biological processes (Supplemental Table 2).

Next, we identified the genes that could affect the network topology. Fifteen bridge and 15 broker genes were initially identified. All 15 bridges and eight out of 15 brokers after bias correction (appeared in less than $20 \%$ of the random networks (Supplemental Table 3 ) due to the fact that commonly studied proteins are more likely to be included in PPI databases (Das and Yu, 2012) were selected. We observed that six

A.

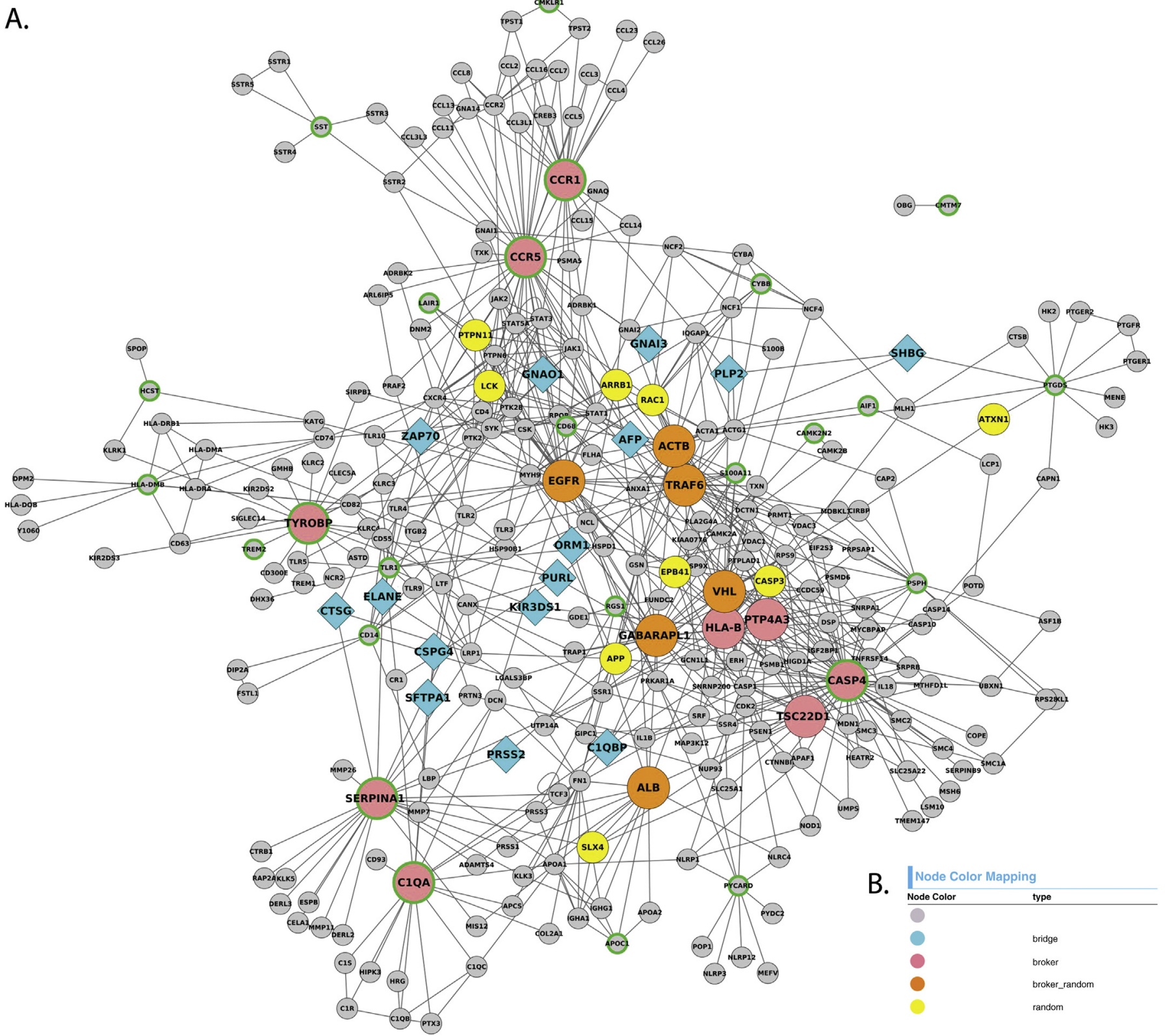

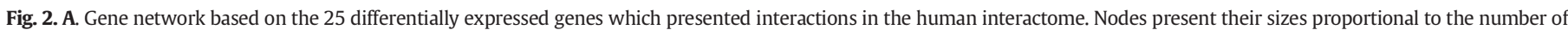
neighbors. B. Legend of colors. The 28 genes are indicated with green border. 
of the 28 differentially expressed genes were brokers in the network: CASP4, TYROBP, CCR1, SERPINA1, CCR5, C1QA.

\section{Discussion}

In this study, gene expression profiling and PPI network in postmortem brain samples of SZ, BD and controls subjects allowed us: 1) to detect common alterations in both diseases when compared to healthy controls, and 2) to characterize molecular alterations that differentiate SZ from BD. Gene network approaches allow the identification of genes that are not necessarily central but have a crucial biological role in signal transduction or in the regulation of the expression of other genes. Typically found in complex diseases, these genes tend to have an intermediate impact in the protein-protein interaction networks as is the case for brokers and bridges (Feldman et al., 2008; Cai et al., 2010).

The integration of gene expression with a PPI network to study patients with schizophrenia and bipolar disorder have been used by other studies. Lee et al analyzed BD and SZ separately in relation to controls revealing genes involved in housekeeping functions (translation, transcription, energy conversion, and metabolism), in brain specific functions ( signal transduction, neuron cell differentiation, and cytoskeleton), and in stress responses (heat shocks and biotic stress) (Lee et al., 2011). A recent whole transcriptome analysis of post-mortem brain tissues identified differentially expressed genes between SZ and BD, compared to control subjects, many of the genes showing concordant expression level, also revealing the involvement of lysosomal function and regulation of actin cytoskeleton with both diseases (Zhao et al., 2014). Different from previous studies, we first identified the common alterations of SZ and BD in relation to control and subsequently focused on the differences between both disorders. The common alterations included 1,264 genes possibly involved with the clinical symptoms shared by SZ and BD. They are involved with nervous system, vasculature and ectoderm development as well as regulation of metabolism and the immune system.

A much smaller subset of 28 genes were found differentially expressed between BD and SZ. Others have noted the small difference in the molecular profiles of $\mathrm{BD}$ and $\mathrm{SZ}$ and the concordant expression level of genes in both diseases in relation to control (Zhao et al., 2014). A comparison of inflammatory monocyte gene expression profiles revealed three subsets of strongly correlating genes characterized by different sets of transcription/MAPK regulating factors, with only one subset showing a different profile: up-regulated in the monocytes of BD but down-regulated in SZ (Drexhage et al., 2010).

Functional analyses of the 28 genes revealed that they are associated with response to stimulus, defense response, immune system process and response to stress. Previous in silico analyses suggested that inflammatory response markers are able to differentiate patients with SZ or BD (Griffiths et al., 2010; Ricklin et al., 2010). A systematic meta-analysis of 13 studies reviewed evidence of peripheral cytokine alterations in BD and found differences between patients and controls and between phases of disease within patients (Munkholm et al., 2013), suggesting that different symptoms are related to activation of different processes within the cell. A meta-analysis based on 40 studies of SZ also indicated that some cytokines may be state markers for acute exacerbations, and others may be trait markers, suggesting that cytokine alterations in schizophrenia may also vary with clinical status (Miller et al., 2011). Accordingly, inflammatory cytokines such as IL6, IL12 and TNF- $\alpha$ were found at high levels in the peripheral blood of patients with SZ (Kunz et al., 2011; Pedrini et al., 2012).

The set of 28 genes had over-representation of genes located at 3p21 in the chemokine receptor gene cluster (CCDC71, CCR1 and CCR5). The $3 \mathrm{p} 21$ locus were pointed as a putative altered locus in BD by GWAS (genome-wide association studies) (McMahon et al., 2010) and an increased susceptibility for late onset SZ was related to a 32-bp deletion in CCR5 (Rasmussen et al., 2006). Down-regulation of CCR1 was also observed in human peripheral mononuclear cells from SZ patients under treatment with antidepressant and antipsychotic (Chertkow et al., 2007). Chemokines have fundamental roles in regulating immune and inflammatory responses. CCR 1 and CCR5 encode members of the $\beta$ chemokine receptor family critical for the recruitment of mononuclear phagocytes to the central nervous system (CNS) in neuroinflammatory diseases (Eltayeb et al., 2007).

Prenatal inflammation is thought to be a risk factor for the development of neuropsychiatric disorders such as schizophrenia and autism spectrum disorders in the unborn child (Gertig and Hanisch, 2014), whereas dysfunctional innate immunity in bipolar disorder could make patients more susceptible to stressful events during life (Najjar et al., 2013; Stertz et al., 2013). Prenatal inflammation triggers the activation of microglia, the tissue-resident macrophages of the central nervous system (CNS) and are active participants in the development and homeostasis of the CNS (Marin-Teva et al., 2004; Takahashi et al., 2005). Using differentially gene expression, co-expression and PPI network topological analyses we found genes related to microglia functions as important genes in the differentiation of SZ and BD: TREM2, TLR1, TYROBP, C1QA, CD68, SERPINA1, CD14, and AIF1.

TREM2 promotes microglial phagocytosis of apoptotic cells (Hsieh et al., 2009). It inhibits macrophage response to ligation of toll-like receptors (TLR) (Ito and Hamerman, 2012). TLR1 plays a fundamental role in activation of innate immunity and is found in microglia, neurons, astrocytes and endothelial cells (Lampron et al., 2013). TREM2 also interacts with TYROBP (DAP12) to maintain brain homeostasis (ParadowskaGorycka and Jurkowska, 2013). The complex DAP12-TREM2 is detected in embryonic day 14 CNS co-localized with markers of microglia/ macrophages (Thrash et al., 2009; Cameron and Landreth, 2010). CD68 can be considered an immunological marker of the density of activated microglia (Monier et al., 2007). CD68-positive microglial cells have frequently been observed in human fetal white matter and present a topographical relationship with growing axons. The protein encoded by CD14 is a surface antigen that mediates the innate immune response. Socially-defeated mice show increased surface expression of several inflammatory proteins including CD14 in microglia and CNS macrophages (Wohleb et al., 2011, 2012). Another protein expressed in microglial cells is AIF1, a marker of activated macrophages (Fukui et al., 2012). SERPIN1 has an important role as a self-defense protein that modulates the activation of microglia (Griffiths et al., 2010).

Microglia is also related to neurodevelopment in neurogenic niches such as the hippocampal dentate gyrus, which contains neural precursor cells (NPCs). In such regions microglia shows a more activated phenotype, detected by CD68 expression (Mosher et al, 2012). Moreover, during development more synapses tagged by complement signaling are pruned by microglia. $C 1 q$ is an upstream member of the complement signaling cascade critical for the elimination of weak or dysfunctional synapses during postnatal neurodevelopment. $\mathrm{C} 1 \mathrm{q}$ is found co-localized with synapses in the developing CNS and its ablation results in an excess number of synapses during adolescence (Stevens et al, 2007). Microglia play a significant role in determining the neuronal and the behavioral responses to chronic psychological stress and, as such, may contribute to the development of stress-related psychopathologies (Hinwood et al., 2012). Altogether, these results suggest that changes in expression of genes involved in microglial function would account to environmental stimulus during neurodevelopment. Also, emerging data show fundamental roles for microglia in the control of neuronal proliferation and differentiation as well as in the formation of synaptic connections, clearance of apoptotic cells and debris, production of trophic factors and in the more long term wiring of neuronal circuits (Graeber, 2010; Hughes, 2012).

In summary, the results from this study revealed genes and biological processes that may underlie differences between SZ and BD, supporting the hypothesis that SZ and BD arise from shared genetic factors, but that the resulting clinical phenotype is modulated by additional alterations mediated by microglia, possibly caused by interference of environmental factors at different times during neurodevelopment 
and early life, and/or epistatic interactions among groups of genes and environment (Rovaris et al., 2013). Our study has limitations since the expression data was provided from post-mortem brain samples and because patients had been medicated. Additionally, it can be conceived that this group of differently expressed genes could represent spurious association due to limited number of cases, regardless all statistical corrections. Lager sample sizes could confirm or refute these findings. Further studies with larger patient and control groups using samples from distinct brain regions are needed to validate our findings and to elucidate how they precisely contribute to disease pathology in these psychiatric disorders.

Supplementary data to this article can be found online at http://dx. doi.org/10.1016/j.schres.2014.10.055.

\section{Funding source}

There are no funding sources to disclose for this work.

\section{Authors' contribution}

$\mathrm{AB}$ analyzed the data and drafted the manuscript. MM helped with the analyses and drafted the manuscript. LL did the PPI network bioinformatics. DMC and CAMF supervised EHO and AF. EHO extracted the RNA. AF and LANB performed the microarray experiments. JAP and PBA participated in the project design and sample acquisition. HB designed the project, supervised the analyses and drafted the manuscript. All authors approved the final version of the manuscript.

\section{Conflict of interest}

The authors declare no conflict of interest.

\section{Funding body agreements and policies}

We thank Stanley Medical Research Institute for providing the tissue samples.

\section{Acknowledgements}

We thank Stanley Medical Research Institute for providing the tissue samples and the patients for donating the samples. We also thank Professor David L. Pauls for critical reading of the manuscript.

\section{References}

Alaerts, M., Del-Favero, J., 2009. Searching genetic risk factors for schizophrenia and bipolar disorder: learn from the past and back to the future. Hum. Mutat. 30 (8), 1139-1152.

Barnett, J.H., Smoller, J.W., 2009. The genetics of bipolar disorder. Neuroscience 164 (1), 331-343.

Bienvenu, O.J., Davydow, D.S., Kendler, K.S., 2011. Psychiatric 'diseases' versus behavioral disorders and degree of genetic influence. Psychol. Med. 41 (1), 33-40.

Cai, J.J., Borenstein, E., Petrov, D.A., 2010. Broker genes in human disease. Genome Biol. Evol. 2, 815-825.

Cameron, B., Landreth, G.E., 2010. Inflammation, microglia, and alzheimer's disease. Neurobiol. Dis. 37 (3), 503-509.

Chertkow, Y., Weinreb, O., Youdim, M.B., Silver, H., 2007. Gene expression changes in peripheral mononuclear cells from schizophrenic patients treated with a combination of antipsychotic with fluvoxamine. Prog. Neuropsychopharmacol. Biol. Psychiatry 31 (7), 1356-1362.

Choi, K.H., Elashoff, M., Higgs, B.W., Song, J., Kim, S., Sabunciyan, S., Diglisic, S., Yolken, R.H., Knable, M.B., Torrey, E.F., Webster, M.J., 2008. Putative psychosis genes in the prefrontal cortex: combined analysis of gene expression microarrays. BMC Psychiatry $8,87$.

Cline, M.S., Smoot, M., Cerami, E., Kuchinsky, A., Landys, N., Workman, C., Christmas, R., Avila-Campilo, I., Creech, M., Gross, B., Hanspers, K., Isserlin, R., Kelley, R., Killcoyne, S., Lotia, S., Maere, S., Morris, J., Ono, K., Pavlovic, V., Pico, A.R., Vailaya, A., Wang, P.L., Adler, A., Conklin, B.R., Hood, L., Kuiper, M., Sander, C., Schmulevich, I., Schwikowski, B., Warner, G.J., Ideker, T., Bader, G.D., 2007. Integration of biological networks and gene expression data using Cytoscape. Nat. Protoc. 2 (10), 2366-2382.

Das, J., Yu, H., 2012. HINT: High-quality protein interactomes and their applications in understanding human disease. BMC Syst. Biol. 6, 92.

Doherty, J.L., O'Donovan, M.C., Owen, M.J., 2012. Recent genomic advances in schizophrenia. Clin. Genet. 81 (2), 103-109.

Drexhage, R.C., van der Heul-Nieuwenhuijsen, L., Padmos, R.C., van Beveren, N., Cohen, D., Versnel, M.A., Nolen, W.A., Drexhage, H.A., 2010. Inflammatory gene expression in monocytes of patients with schizophrenia: overlap and difference with bipolar disorder. A study in naturalistically treated patients. Int. J. Neuropsychopharmacol. 13 (10), 1369-1381.

Eltayeb, S., Berg, A.L., Lassmann, H., Wallstrom, E., Nilsson, M., Olsson, T., EricssonDahlstrand, A., Sunnemark, D., 2007. Temporal expression and cellular origin of CC chemokine receptors CCR1, CCR2 and CCR5 in the central nervous system: Insight into mechanisms of MOG-induced EAE. J. Neuroinflammation 4.
Feldman, I., Rzhetsky, A., Vitkup, D., 2008. Network properties of genes harboring inherited disease mutations. Proc. Natl. Acad. Sci. U. S. A. 105 (11), 4323-4328.

Fukui, M., Tanaka, M., Toda, H., Asano, M., Yamazaki, M., Hasegawa, G., Imai, S., Fujinami, A., Ohta, M., Nakamura, N., 2012. The serum concentration of allograft inflammatory factor- 1 is correlated with metabolic parameters in healthy subjects. Metabolism 61 (7), 1021-1025

Gertig, U., Hanisch, U.K., 2014. Microglial diversity by responses and responders. Front Cell. Neurosci. 8.

Graeber, M.B., 2010. Changing Face of Microglia. Science 330 (6005), 783-788.

Griffiths, M.R., Gasque, P., Neal, J.W., 2010. The regulation of the CNS innate immune response is vital for the restoration of tissue homeostasis (repair) after acute brain injury: a brief review. Int. J. Inflamm. 2010, 151097.

Hinwood, M., Morandini, J., Day, T.A., Walker, F.R., 2012. Evidence that Microglia Mediate the Neurobiological Effects of Chronic Psychological Stress on the Medial Prefrontal Cortex. Cereb. Cortex 22 (6), 1442-1454.

Hsieh, C.L., Koike, M., Spusta, S.C., Niemi, E.C., Yenari, M., Nakamura, M.C., Seaman, W.E., 2009. A role for TREM2 ligands in the phagocytosis of apoptotic neuronal cells by microglia. J. Neurochem. 109 (4), 1144-1156.

Hughes, V., 2012. The Constant Gardeners. Nature 485 (7400), 570-572.

Ito, H., Hamerman, J.A., 2012. TREM-2, triggering receptor expressed on myeloid cell-2, negatively regulates TLR responses in dendritic cells. Eur. J. Immunol. 42 (1), 176-185.

Ivleva, E.I., Morris, D.W., Moates, A.F., Suppes, T., Thaker, G.K., Tamminga, C.A., 2010. Genetics and intermediate phenotypes of the schizophrenia-bipolar disorder boundary. Neurosci. Biobehav. Rev. 34 (6), 897-921.

Iwamoto, K., Bundo, M., Kato, T., 2005. Altered expression of mitochondria-related genes in postmortem brains of patients with bipolar disorder or schizophrenia, as revealed by large-scale DNA microarray analysis. Hum. Mol. Genet. 14 (2), 241-253.

Kerrien, S., Aranda, B., Breuza, L., Bridge, A., Broackes-Carter, F., Chen, C., Duesbury, M., Dumousseau, M., Feuermann, M., Hinz, U., Jandrasits, C., Jimenez, R.C., Khadake, J., Mahadevan, U., Masson, P., Pedruzzi, I., Pfeiffenberger, E., Porras, P., Raghunath, A. Roechert, B., Orchard, S., Hermjakob, H., 2012. The IntAct molecular interaction database in 2012. Nucleic Acids Res. 40 (Database issue), D841-D846.

Keshava Prasad, T.S., Goel, R., Kandasamy, K., Keerthikumar, S., Kumar, S., Mathivanan, S. Telikicherla, D., Raju, R., Shafreen, B., Venugopal, A., Balakrishnan, L., Marimuthu, A. Banerjee, S., Somanathan, D.S., Sebastian, A., Rani, S., Ray, S., Harrys Kishore, C.J. Kanth, S., Ahmed, M., Kashyap, M.K., Mohmood, R., Ramachandra, Y.L., Krishna, V., Rahiman, B.A., Mohan, S., Ranganathan, P., Ramabadran, S., Chaerkady, R., Pandey, A., 2009. Human Protein Reference Database-2009 update. Nucleic Acids Res. 37 (Database issue), D767-D772.

Kunz, M., Cereser, K.M., Goi, P.D., Fries, G.R., Teixeira, A.L., Fernandes, B.S., Belmonte-deAbreu, P.S., Kauer-Sant'Anna, M., Kapczinski, F., Gama, C.S., 2011. Serum levels of IL6, IL-10 and TNF-alpha in patients with bipolar disorder and schizophrenia: differences in pro- and anti-inflammatory balance. Rev. Bras. Psiquiatr. 33 (3), 268-274.

Lampron, A., Elali, A., Rivest, S., 2013. Innate Immunity in the CNS: Redefining the Relationship between the CNS and Its Environment. Neuron 78 (2), 214-232.

Lee, S.A., Tsao, T.T., Yang, K.C., Lin, H., Kuo, Y.L., Hsu, C.H., Lee, W.K., Huang, K.C., Kao, C.Y. 2011. Construction and analysis of the protein-protein interaction networks for schizophrenia, bipolar disorder, and major depression. BMC Bioinforma. 12 (Suppl. 13), S20.

Licata, L., Briganti, L., Peluso, D., Perfetto, L., Iannuccelli, M., Galeota, E., Sacco, F., Palma, A. Nardozza, A.P., Santonico, E., Castagnoli, L., Cesareni, G., 2012. MINT, the molecular interaction database: 2012 update. Nucleic Acids Res. 40 (Database issue) D857-D861.

Lichtenstein, P., Yip, B.H., Björk, C., Pawitan, Y., Cannon, T.D., Sullivan, P.F., Hultman, C.M 2009. Common genetic determinants of schizophrenia and bipolar disorder in Swedish families: a population-based study. Lancet 373 (9659), 234-239.

Lin, C.Y., Sawa, A., Jaaro-Peled, H., 2012. Better understanding of mechanisms of schizophrenia and bipolar disorder: from human gene expression profiles to mouse models. Neurobiol. Dis. 45 (1), 48-56.

Maier, W., Zobel, A., Wagner, M., 2006. Schizophrenia and bipolar disorder: differences and overlaps. Curr. Opin. Psychiatry 19 (2), 165-170.

Marin-Teva, J.L., Dusart, I., Colin, C., Gervais, A., van Rooijen, N., Mallat, M., 2004. Microglia promote the death of developing Purkinje cells. Neuron 41 (4), 535-547.

McMahon, FJ Akula, N Schulze, T.G Muglia, P. Tozzi, F, Detera-Wadleigh, S.D Steele C.J., Breuer, R., Strohmaier, J., Wendland, J.R., Mattheisen, M., Muhleisen, T.W. Maier, W., Nothen, M.M., Cichon, S., Farmer, A., Vincent, J.B., Holsboer, F., Preisig, M. Rietschel, M., 2010. Meta-analysis of genome-wide association data identifies a risk locus for major mood disorders on 3p21.1. Nat. Genet. 42 (2), 128-131.

Merikangas, K.R., Akiskal, H.S., Angst, J., Greenberg, P.E., Hirschfeld, R.M., Petukhova, M. Kessler, R.C., 2007. Lifetime and 12-month prevalence of bipolar spectrum disorder in the National Comorbidity Survey replication. Arch. Gen. Psychiatry 64 (5), 543-552.

Miller, B.J., Buckley, P., Seabolt, W., Mellor, A., Kirkpatrick, B., 2011. Meta-analysis of cytokine alterations in schizophrenia: clinical status and antipsychotic effects. Biol. Psychiatry 70 (7), 663-671.

Monier, A., Adle-Biassette, H., Delezoide, A.L., Evrard, P., Gressens, P., Verney, C., 2007 Entry and distribution of microglial cells in human embryonic and fetal cerebral cortex. J. Neuropathol. Exp. Neurol. 66 (5), 372-382.

Mosher, K.I., Andres, R.H., Fukuhara, T., Bieri, G., Hasegawa-Moriyama, M., He, Y., Guzman, R., Wyss-Coray, T., 2012. Neural progenitor cells regulate microglia functions and activity. Nat. Neurosci. 15 (11), 1485-1487.

Moskvina, V., Craddock, N., Holmans, P., Nikolov, I., Pahwa, J.S., Green, E., Owen, M.J. O'Donovan, M.C., Consortium, W.T.C.C., 2009. Gene-wide analyses of genome-wide association data sets: evidence for multiple common risk alleles for schizophrenia and bipolar disorder and for overlap in genetic risk. Mol. Psychiatry 14 (3), 252-260. 
Munkholm, K., Vinberg, M., Vedel Kessing, L., 2013. Cytokines in bipolar disorder: a systematic review and meta-analysis. J. Affect. Disord. 144 (1-2), 16-27.

Najjar, S., Pearlman, D.M., Alper, K., Najjar, A., Devinsky, O., 2013. Neuroinflammation and psychiatric illness. J. Neuroinflammation 10, 43.

O'Donovan, M.C., Craddock, N., Norton, N., Williams, H., Peirce, T., Moskvina, V., Nikolov, I. Hamshere, M., Carroll, L., Georgieva, L., Dwyer, S., Holmans, P., Marchini, J.L., Spencer, C.C., Howie, B., Leung, H.T., Hartmann, A.M., Möller, H.J., Morris, D.W., Shi, Y., Feng, G. Hoffmann, P., Propping, P., Vasilescu, C., Maier, W., Rietschel, M., Zammit, S. Schumacher, J., Quinn, E.M., Schulze, T.G., Williams, N.M., Giegling, I., Iwata, N., Ikeda, M., Darvasi, A., Shifman, S., He, L., Duan, J., Sanders, A.R., Levinson, D.F., Gejman, P.V., Cichon, S., Nöthen, M.M., Gill, M., Corvin, A., Rujescu, D., Kirov, G., Owen, M.J., Buccola, N.G., Mowry, B.J., Freedman, R., Amin, F., Black, D.W., Silverman, J.M., Byerley, W.F., Cloninger, C.R., Collaboration, M.G.o.S., 2008. Identification of loci associated with schizophrenia by genome-wide association and follow-up. Nat. Genet. 40 (9), 1053-1055.

Paradowska-Gorycka, A., Jurkowska, M., 2013. Structure, expression pattern and biological activity of molecular complex TREM-2/DAP12. Hum. Immunol. 74 (6), 730-737.

Pedrini, M., Massuda, R., Fries, G.R., Pasquali, M.A.D., Schnorr, C.E., Moreira, J.C.F., Teixeira, A.L., Lobato, M.I.R., Walz, J.C., Belmonte-de-Abreu, P.S., Kauer-Sant'Anna, M., Kapczinski, F., Gama, C.S., 2012. Similarities in serum oxidative stress markers and inflammatory cytokines in patients with overt schizophrenia at early and late stages of chronicity. J. Psychiatr. Res. 46 (6), 819-824.

Rasmussen, H.B., Timm, S., Wang, A.G., Soeby, K., Lublin, H., Fenger, M., Hemmingsen, R. Werge, T., 2006. Association between the CCR5 32-bp deletion allele and late onset of schizophrenia. Am. J. Psychiatry 163 (3), 507-511.

Ricklin, D., Hajishengallis, G., Yang, K., Lambris, J.D., 2010. Complement: a key system for immune surveillance and homeostasis. Nat. Immunol. 11 (9), 785-797.

Rovaris, D.L., Mota, N.R., Callegari-Jacques, S.M., Bau, C.H.D., 2013. Approaching "phantom heritability" in psychiatry by hypothesis-driven gene-gene interactions. Front. Hum. Neurosci. 7.

Saeed, A.I., Sharov, V., White, J., Li, J., Liang, W., Bhagabati, N., Braisted, J., Klapa, M., Currier T., Thiagarajan, M., Sturn, A., Snuffin, M., Rezantsev, A., Popov, D., Ryltsov, A., Kostukovich, E., Borisovsky, I., Liu, Z., Vinsavich, A., Trush, V., Quackenbush, J., 2003. TM4: a free, open-source system for microarray data management and analysis. BioTech. 34 (2), 374-378.

Shao, L., Vawter, M.P., 2008. Shared gene expression alterations in schizophrenia and bipolar disorder. Biol. Psychiatry 64 (2), 89-97.

Silva, A.R., Grinberg, L.T., Farfel, J.M., Diniz, B.S., Lima, L.A., Silva, P.J., Ferretti, R.E., Rocha, R.M., Filho, W.J., Carraro, D.M., Brentani, H., 2012. Transcriptional alterations related to neuropathology and clinical manifestation of Alzheimer's disease. PLoS One 7 (11), e48751.

Stertz, L., Magalhaes, P.V.S., Kapczinski, F., 2013. Is bipolar disorder an inflammatory condition? The relevance of microglial activation. Curr. Opin. Psychiatry 26 (1), $19-26$.
Stevens, B., Allen, N.J., Vazquez, L.E., Howell, G.R., Christopherson, K.S., Nouri, N., Micheva, K.D., Mehalow, A.K., Huberman, A.D., Stafford, B., Sher, A., Litke, A.M., Lambris, J.D., Smith, S.J., John, S.W., Barres, B.A., 2007. The classical complement cascade mediates CNS synapse elimination. Cell 131 (6), 1164-1178.

Sullivan, P.F., Kendler, K.S., Neale, M.C., 2003. Schizophrenia as a complex trait: evidence from a meta-analysis of twin studies. Arch. Gen. Psychiatry 60 (12), 1187-1192.

Takahashi, K., Rochford, C.D.P., Neumann, H., 2005. Clearance of apoptotic neurons without inflammation by microglial triggering receptor expressed on myeloid cells-2. J. Exp. Med. 201 (4), 647-657.

Thrash, J.C., Torbett, B.E., Carson, M.J., 2009. Developmental Regulation of TREM2 and DAP12 Expression in the Murine CNS: Implications for Nasu-Hakola Disease. Neurochem. Res. 34 (1), 38-45.

Torrey, E.F., 2000. Community care and schizophrenia. Lancet 355 (9217), 1827-1828.

Williams, H.J., Craddock, N., Russo, G., Hamshere, M.L., Moskvina, V., Dwyer, S., Smith, R.L., Green, E., Grozeva, D., Holmans, P., Owen, M.J., O'Donovan, M.C., 2011a. Most genome-wide significant susceptibility loci for schizophrenia and bipolar disorder reported to date cross-traditional diagnostic boundaries. Hum. Mol. Genet. 20 (2), 387-391.

Williams, H.J., Norton, N., Dwyer, S., Moskvina, V., Nikolov, I., Carroll, L., Georgieva, L., Williams, N.M., Morris, D.W., Quinn, E.M., Giegling, I., Ikeda, M., Wood, J., Lencz, T., Hultman, C., Lichtenstein, P., Thiselton, D., Maher, B.S., Malhotra, A.K., Riley, B., Kendler, K.S., Gill, M., Sullivan, P., Sklar, P., Purcell, S., Nimgaonkar, V.L., Kirov, G., Holmans, P., Corvin, A., Rujescu, D., Craddock, N., Owen, M.J., O'Donovan,, M.C., Molecular Genetics of Schizophrenia Collaboration (MGS), International Schizophrenia Consortium (ISC), S.G.E.-p, G. R. O.UP, 2011b. Fine mapping of ZNF804A and genome-wide significant evidence for its involvement in schizophrenia and bipolar disorder. Mol. Psychiatry 16 (4), 429-441.

Wohleb, E.S., Hanke, M.L., Corona, A.W., Powell, N.D., Stiner, L.M., Bailey, M.T., Nelson, R.J., Godbout, J.P., Sheridan, J.F., 2011. beta-Adrenergic Receptor Antagonism Prevents Anxiety-Like Behavior and Microglial Reactivity Induced by Repeated Social Defeat. J. Neurosci. 31 (17), 6277-6288.

Wohleb, E.S., Fenn, A.M., Pacenta, A.M., Powell, N.D., Sheridan, J.F., Godbout, J.P., 2012. Peripheral innate immune challenge exaggerated microglia activation, increased the number of inflammatory CNS macrophages, and prolonged social withdrawal in socially defeated mice. Psychoneuroendocrinology 37 (9), 1491-1505.

Zhang, B., Kirov, S., Snoddy, J., 2005. WebGestalt: an integrated system for exploring gene sets in various biological contexts. Nucleic Acids Res. 33 (Web Server issue), W741-W748.

Zhao, Z., Xu, J., Chen, J., Kim, S., Reimers, M., Bacanu, S.A., Yu, H., Liu, C., Sun, J., Wang, Q., Jia, P., Xu, F., Zhang, Y., Kendler, K.S., Peng, Z., Chen, X., 2014. Transcriptome sequencing and genome-wide association analyses reveal lysosomal function and actin cytoskeleton remodeling in schizophrenia and bipolar disorder. Mol. Psychiatry http://dx.doi. org/10.1038/mp.2014.82. 